\title{
EDITORIAL: ON REMEMBERING
}

\author{
Christopher Fox
}

This issue feels more retrospective than usual. Ten years after Stockhausen's death Robin Maconie reflects on the composer's achievement in a remarkable article that ranges across Stockhausen's entire life and work and positions him as a 'moral realist'. We also recall the life and work of another great Stockhausen scholar, the musicologist Richard Toop, who died earlier this year.

These acts of remembrance are part of the process by which more or less value is attached to music and musicians. We remember Stockhausen because his music continues to excite, delight, inspire, even annoy listeners. Ten years after his death it is clear that works from across his career - from the glittering inventions of the 1950s through to the haunted rituals of the KLANG series - are securing their place in the repertoire, and the Holland Festival's 2019 aus LICHT project will go some way to determining whether the sevenday cycle of LICHT operas is added to this musical pantheon. We remember Richard Toop because his razor-sharp critical insights opened up this, and much other, music.

This same process, choosing what to remember from all the music that is produced, works in the other direction too: reputations fade, and many musicians' work never even acquires a reputation. Or, steadily, stealthily, persistence can generate a body of remembering so substantial that, like the elephant in the room, it must eventually attract the recognition it deserves. Fifteen years ago Christian Wolff was a featured composer at the 2002 Huddersfield Contemporary Music Festival, the first time any British music festival had devoted this sort of sustained attention to his music. The programming was inspired, encompassing work from every period of Wolff s career indeterminate, political, orchestral - and during the festival Wolff gave two extended interviews, one from the stage of the Lawrence Batley Theatre, the other for Radio New Zealand.

These survive, and can now be published in TEMPO, because James Gardner remembered them and, in the case of the platform interview, sat in the audience with a DAT recorder. Later he transcribed both that recording and his radio interview and has now edited them together to produce the text published for the first time here. Wolff is also featured in the review section of this issue where Evan Johnson discusses a new volume of his collected writings and Oliver Thurley reviews Apartment House's premiere of Resistance, Wolffs most recent large-scale work. Resistance was commissioned as a companion piece for Cage's Concert for piano and orchestra and, like that work, is something of a compendium of compositional techniques; since the Huddersfield interviews take a similarly compendious approach it seemed appropriate to include them as well.

Remembering lies at the heart of what musicians do in performance and in most of the world's musical cultures performers rely entirely on their memories. Even in the musical culture that TEMPO serves there is a point in the development of most 
performances at which the score becomes an aide memoire. But the interface between score and performer has the potential to allow many different sorts of interaction, something that Christopher Williams explores in his 'lexical improvisation after Bob Ostertag'. Williams makes a provocative distinction between notation and scores, the former being 'casual, almost benevolent', the latter marking 'winners and losers', and readers are free to decide into which category the artworks by Anton Lukoszevieze that punctuate this issue might fall.

TEMPO was published for many years by the music publishing company Boosey and Hawkes. They had no hesitation in making extensive use of music examples, more often than not from the scores of their own composers, and since Cambridge University Press acquired TEMPO its pages of text have continued to be broken up by music examples, provided by the publishers of the scores under discussion. It's an act of reciprocal generosity: nobody involved in TEMPO is doing it for the money but rather to make a contribution to the understanding of new music; by freely supplying music examples music publishers help to foster that understanding because to a musically literate reader a score extract is worth many hundreds of words.

In the current issue, however, this mutually supportive relationship has been damaged by a publisher who has chosen to 'protect their investment' by charging for the four examples we are using. Does this signal a new era in which it will become prohibitively expensive for music scholarship to include score extracts? I doubt it, but it is a symptom of the many uncertainties that trouble music publishing. How can a publisher convert intellectual property into cash in the age of digital reproduction? How does an industry that grew out of the invention of music printing survive when printing is becoming redundant? Above all, how do music publishers protect their historic function as the gatekeepers of compositional excellence when the creators of the most interesting new music choose to manage their own copyrights?

This last question is also addressed in Neil Smith and Rachel Thwaites' survey of composition competitions, one of the means by which composers are enabled to 'emerge'. A few years ago I was on a panel discussing how young composers might work with music publishers. 'How will you find out about me?' asked one young composer in the audience. 'We just will,' blithely answered the director of a distinguished publishing house. But mostly they don't and these days it really doesn't matter as, steadily, stealthily, we find more and more ways not only to make music and disseminate it, but also to hear it and remember it.

$$
\star \star \star
$$

The news of Klaus Huber's death, on 2 October 2017, arrived just as this issue of TEMPO was about to go to press. Klaus Huber was born in Bern on 30 November 1924 and centred his life in and around Switzerland, teaching composition in Basel from 1962 to 1972 and then in Freiburg until 1990. His work first gained international attention in 1959 when his chamber cantata Des Engels Anredung an die Seele (1957) was performed at the ISCM World Music Days and his web-site (www.klaushuber.com) lists well over a hundred other works, many of them ambitious large-scale works.

It is this ambition that perhaps explains why Huber's music is not better known outside the German-speaking world. Erniedrigt - 
Geknechtet - Verlassen - Verachtet... (1982), for example, first given in its complete form in Donaueschingen in 1983, lasts seventy minutes and is scored for four solo vocalists, chamber choir, choir, and fifty instrumentalists in seven groups, with four conductors. But as Matthias Knauer's 1985 film of the work, El Pueblo nunca muere, demonstrates, it is a work whose multiple ensembles and multiple texts (five different sources, including the liberation theologian Ernesto Cardenal, and the African-American political activist George Jackson) are combined with considerable expressive power.

Such a coming together of leftist humanitarian sympathies, an elaborate modernist musical vocabulary, and the generous resources of continental European new music festivals was not uncommon in the latter decades of the twentieth century, but Huber's compositional output reveals far more than the usual careerist accumulation of status symbols. His interests reached deep into other cultures and other eras, something demonstrated not just by the eclectic range of texts in his works for voice but also by his growing willingness to integrate alien elements within a musical language whose roots remained firmly in European modernism. Thus QUOD EST PAX? - Vers la raison due coeur (2008) adds Arabic percussion to another largescale work for singers and orchestra, while in the much more intimate Intarsioso (2009) contralto and string quartet are joined by the curiously exotic sonorities of a fortepiano.

Huber will be remembered for the generosity of his support for many generations of younger composers but, above all, for the generosity of his musical imagination. His music is rich, varied, dramatic, lyrical, and always motivated by a profound fascination with what it means to be human and to live in our world. 